\title{
Na kaj moramo biti pozorni, ko izbiramo feromonski pripravek za ulov osmerozobega smrekovega lubadarja v režaste pasti?
}

\author{
Nina ŠRAMEL ${ }^{1}$, Andreja KAVČIČ ${ }^{1}$, Marija KOLŠEK ${ }^{2}$, Maarten DE GROOT $^{\text {* }}$
}

\section{Povzetek}

$\mathrm{V}$ prispevku povzemamo ugotovitve raziskave, ki je bila narejena v sodelovanju med Gozdarskim inštitutom Slovenije, Oddelkom za varstvo gozdov in Zavodom za gozdove Slovenije (Šramel in sod., 2021). Cilj raziskave je bila primerjava ulova v režaste pasti ob uporabi različnih feromonskih pripravkov za privabljanje osmerozobega smrekovega lubadarja, Ips typographus (Linnaeus, 1758). Izdelan je bil indeks, s katerim je mogoče določiti učinkovitost feromonskega pripravka za osmerozobega smrekovega lubadarja. Ugotovili smo, da se pripravki med seboj razlikujejo po učinkovitosti, njihova učinkovitost pa ni sorazmerna s ceno.

Ključne besede: Ips typographus, feromonski pripravki, spremljanje, učinkovitost, stroški.

\section{Uvod}

V zadnjih desetletjih smo priča naraščajočim številom prenamnožitev osmerozobega smrekovega lubadarja tako v Evropi kot tudi v Sloveniji, zaradi česar beležimo visoko sanitarno sečnjo (de Groot in sod., 2019). Učinkovit sistem spremljanja dinamike populacije osmerozobega smrekovega lubadarja nam lahko pomaga predvideti njegove prenamnožitve, kar nam lahko omogoči pravočasno izvajanje ukrepov in preprečitev širjenja žarišč. Pomemben element pri načrtovanju spremljanja osmerozobega smrekovega lubadarja s feromonskimi pastmi je izbira feromonskega pripravka. Ugotovljeno je bilo, da so za privabljanje osmerozobega smrekovega lubadarja glavne kemične komponente ipsdienol, metilbutenol in cis-verbenol (Bakke in sod., 1977). Na trgu so na voljo različni feromonski pripravki, ki vsebujejo omenjene komponente. Vendar pa niso vse mešanice enako učinkovite. Feromonski pripravki se razlikujejo po obliki (pivnik, ampula), dobi trajanja oz. učinkovanja na terenu, ceni, ter kot kažejo raziskave, tudi po učinkovitosti (Pernek, 2002, Göktürk in sod., 2005, Galko in sod., 2010). Med pregledom literature smo ugotovili, da je zelo malo študij, ki bi vključevale tudi ekonomski vidik uporabe feromonskih pripravkov. Ker v Sloveniji feromonske pripravke za spremljanje dinamike populacije osmerozobega smrekovega lubadarja nabavljamo na podlagi javnih naročil, smo želeli ugotoviti, ali je dražji feromonski pripravek tudi bolj učinkovit oz. kako je cena povezana $\mathrm{z}$ učinkovitostjo feromonskega pripravka. V raziskavi Šramel in sod. (2021) smo primerjali ulov v pasti, opremljene s petimi različnimi komercialno dostopnimi feromonskimi pripravki. Pri- pravili smo indeks, ki omogoča primerjavo med feromonskimi pripravki na podlagi njihovih lastnosti (učinkovitost, občutljivost, selektivnost) in cene.

\section{Metode dela}

Poskus smo izvajali od začetka marca do konca septembra 2019. Uporabili smo 50 enojnih režastih pasti tipa Theysohn in feromonske pripravke Pheroprax ${ }^{\circledR}$, IT Ecolure Extra ${ }^{\circledR}$, Ipstyp ${ }^{\circledR}$, Ipsowit ${ }^{\circledR}$ in Typosan ${ }^{\circledR}$. Pasti smo postavili v smrekovih gozdovih, ki so bili v pretekli sezoni (december 2017) prizadeti zaradi vetroloma (testne lokacije, 25 pasti), in v vetrolomu nepoškodovanih smrekovih sestojih (kontrolne lokacije, 25 pasti). Pasti so bile na vseh lokacijah postavljene enakomerno in naključno, ter med seboj oddaljene najmanj $1 \mathrm{~km}$. Populacija osmerozobega smrekovega lubadarja je bila pod pragom prenamnožitve in v sestoju je bila lesna zaloga navadne smreke (Picea abies) $70 \%$ ali več. Prav tako so bile primerljive druge ekološke razmere (drevesna sestava, nadmorska višina, naklon, osončenost, povprečna mesečna temperatura zraka, povprečna mesečna količina padavin). Pasti so bile praznjene na 7 do 14 dni, odvisno od temperature. V kolikor je bila temperatura višja od $24^{\circ} \mathrm{C}$, so se pasti praznile na vsakih 7 dni. Izbira lokacij, praznjenje in menjava feromonskih pripravkov so bili izvedeni s strani revirnih gozdarjev Zavoda za gozdove Slovenije (ZGS). Raziskavo smo izvajali v gozdnogospodarskem območju (GGO) Kranj (20 pasti) in GGO Slovenj Gradec (30 pasti). V vsakem GGO smo izbrali testno in kontrolno lokacijo. V GGO Kranj (Slika 1) so bile testne pasti od kontrolnih oddaljene $6,5 \mathrm{~km}$ in v GGO Slovenj Gradec (Slika 2) 3,5 km. Testni lokaciji $\mathrm{v}$ raziskavi sta bili Jezersko (10 pasti) v krajevni enoti (KE) Preddvor in južni del Pohorja (15 pasti) v KE Slovenj Gradec. Kontrolni lokaciji pa sta bili izbrani v KE Tržič na območju Loma (6 pasti) in Podljubela (4 pasti), ter na južnem pobočju nad Mislinjo (15 pasti) v KE Mislinja. V letu 2018 je bila populacija osmerozobih smrekovih podlubnikov na vseh izbranih lokacijah pod pragom prenamnožitve. V GGO Kranj smo imeli 2 ponovitvi $\mathrm{v}$ testni in kontrolni lokaciji, v GGO Slovenj Gradec 3 ponovitve - vsega skupaj 10 ponovitev za vsak feromonski pripravek. Na vsaki lokaciji smo uporabili vseh pet feromonskih pripravkov. Metode dela so podrobneje predstavljene v izvirnem delu (Šramel in sod., 2021).

\footnotetext{
${ }^{1}$ Gozdarski inštitut Slovenije, Večna pot 2,1000 Ljubljana; *maarten.degroot@gozdis.si

${ }^{2}$ Zavod za Gozdove Slovenije, Večna pot 2, 1000 Ljubljana
} 


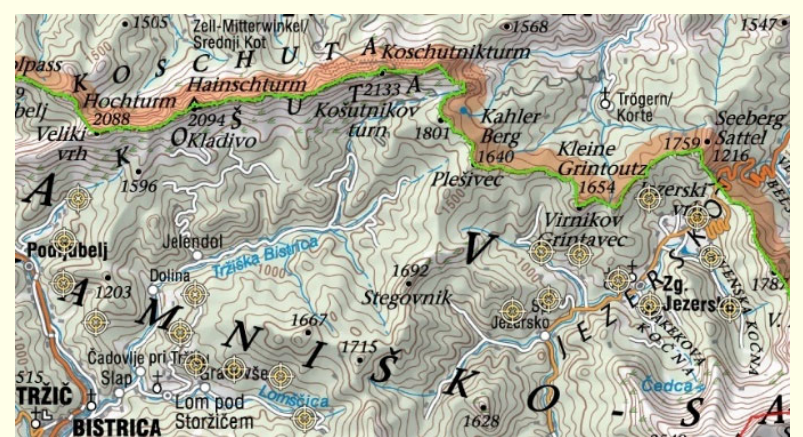

Slika 1: Lokacije pasti v GGO Kranj.

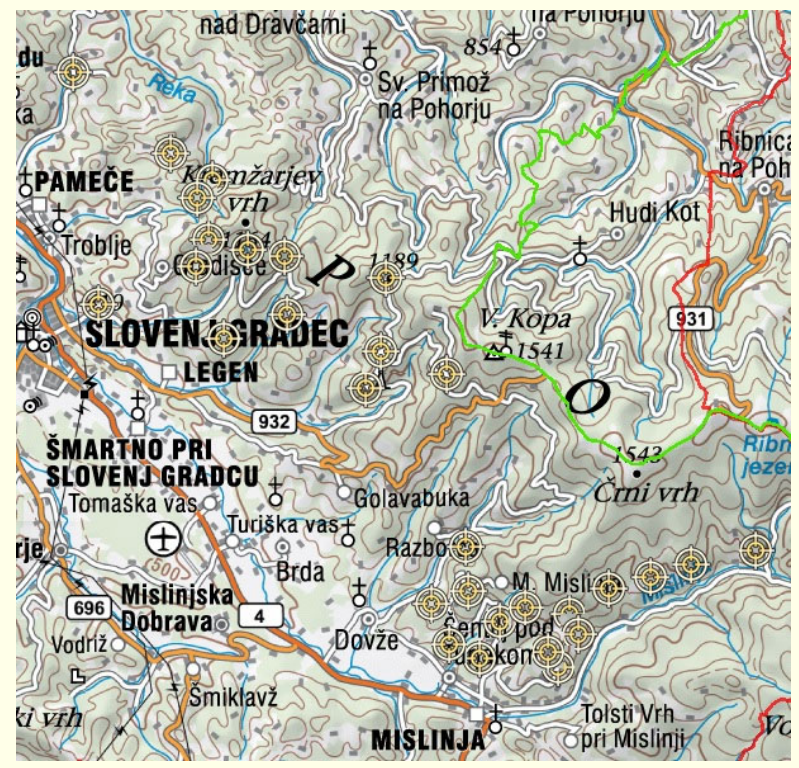

Slika 2: Lokacije pasti v GGO Slovenj Gradec.

\section{Rezultati}

\section{Ulov v pasti}

Skupno smo ujeli 554.822 osebkov osmerozobega smrekovega lubadarja. Od tega je bilo največ osebkov ujetih v pasti $\mathrm{s}$ feromonskim pripravkom IT Ecolure Extra $^{\circledR}$ (155.083 osebkov), sledile so pasti $z$ Ipsowit ${ }^{\circledR}$ (147.844 osebkov), Pheroprax ${ }^{\circledR}$ (143.232 osebkov), Ipstyp $^{\circledR}$ (67.252 osebkov) in Typosan ${ }^{\circledR}$ (41.411 osebkov) (Slika 3). Število ujetih osebkov osmerozobega smrekovega lubadarja se je statistično značilno razlikovalo le med feromonskimi pripravki IT Ecolure Extra ${ }^{\circledR}$, Ipsowit $^{\mathbb{R}}$ in Pheroprax ${ }^{\circledR} \mathrm{v}$ primerjavi z Ipstyp ${ }^{\circledR}$ in Typo$\operatorname{san}^{\circledR}$.

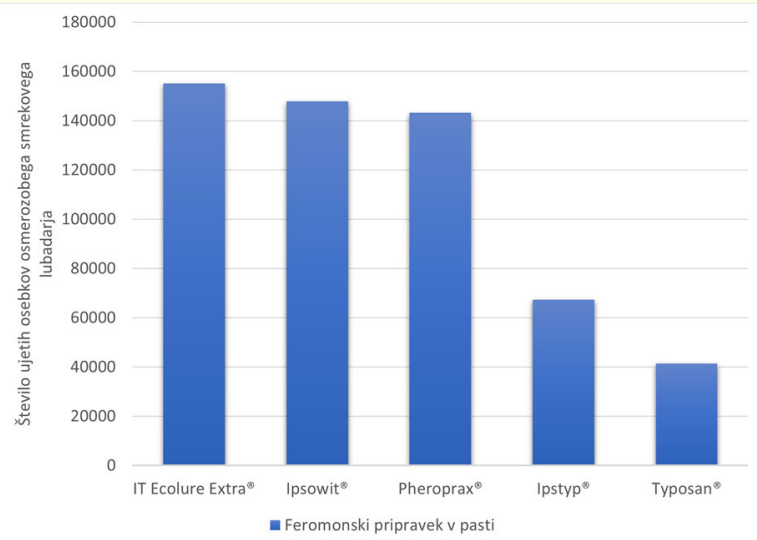

Slika 3: Število ujetih osebkov osmerozobega smrekovega lubadarja glede na feromonski pripravek.
Pri analizi smo zabeležili skupno 32.024 primerkov neciljnih organizmov (stranski ulov), od tega je bilo 29.741 predstavnikov reda hroščev (Coleoptera), 2.283 osebkov pa je pripadalo drugim skupinam žuželk (Slika 4). Med ulovljenimi hrošči smo našli tudi 46 primerkov plenilcev osmerozobega smrekovega lubadarja.

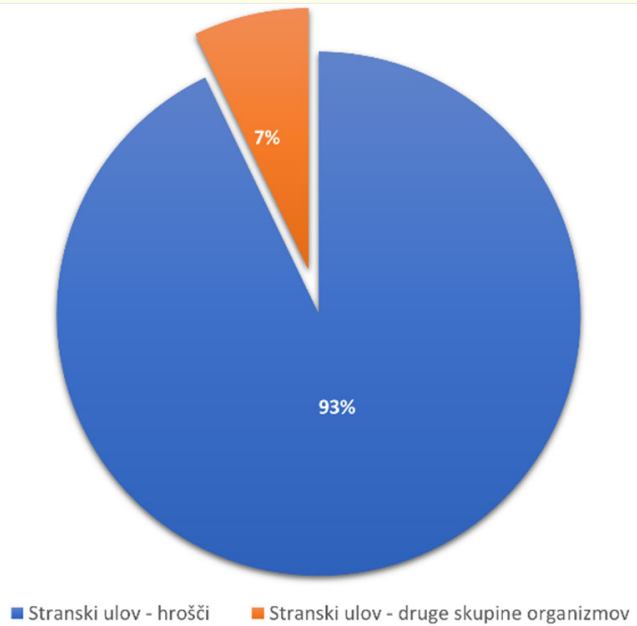

Slika 4: Struktura stranskega ulova.

Stranski ulov vrst je bil sorazmeren z ulovom osmerozobega smrekovega lubadarja. Največji delež stranskega ulova smo zabeležili v pasteh s feromonskim pripravkom IT Ecolure Extra ${ }^{\circledR}$ (10.634 osebkov), sledile so pasti $\mathrm{s}$ feromonskimi pripravki Ipsowit ${ }^{\mathbb{B}}$ (8.456 osebkov), Pheroprax ${ }^{\circledR}$ (6.221 osebkov), Ipstyp ${ }^{\circledR}$ (3.603 osebkov) in Typosan ${ }^{\circledR}$ (3.110 osebkov) (Slika 5). Razlike v količini stranskega ulova med pastmi z različnimi feromonskimi pripravki niso bile statistično značilne. Kljub temu, da je bilo število ujetih plenilcev osmerozobega smrekovega lubadarja zelo majhno (6 osebkov Nemosoma elongatum, 26 osebkov Thanasimus femoralis, 4 osebki $T$. formicarius in 10 osebkov Thanasimus spp.), je bilo njihovo število $\mathrm{v}$ pasteh $\mathrm{s}$ feromonskima pripravkoma Ipstyp ${ }^{\circledR}$ in IT Ecolure Extra ${ }^{\circledR}$ statistično značilno večje kot $\mathrm{v}$ pasteh, opremljenih z ostalimi feromonskimi pripravki.

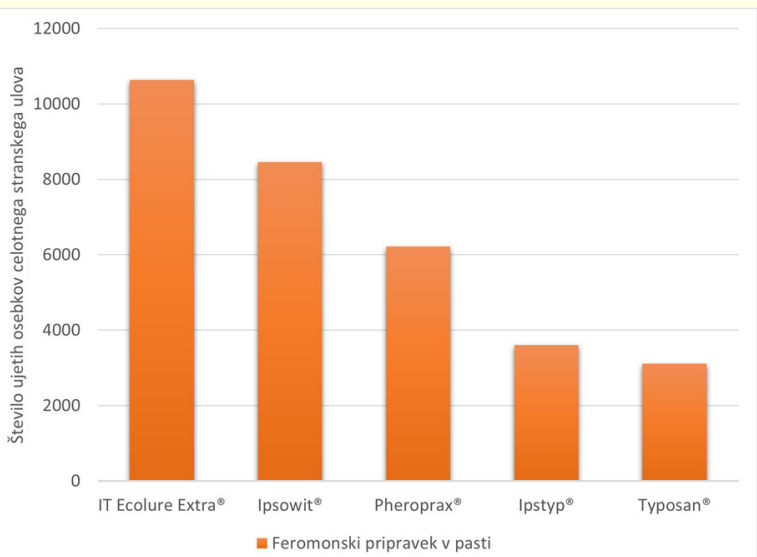

Slika 5: Število ujetih organizmov stranskega ulova glede na feromonski pripravek.

Analiza je pokazala pričakovane razlike $\mathrm{v}$ ulovu osmerozobega smrekovega lubadarja med testnimi in kontrolnimi lokacijami. Nepričakovano, pa je analiza 
pokazala razlike med obema GGO. Celoten ulov osmerozobega smrekovega lubadarja ne glede na vrsto feromonskega pripravka je bil na testnih lokacijah za 38,8 \% višji kot na kontrolnih lokacijah (Slika 6). To kaže na povečanje številčnosti populacije osmerozobega smrekovega lubadarja $\mathrm{v}$ drugi vegetacijski dobi po vetrolomu, ki se je zgodil konec leta 2017.

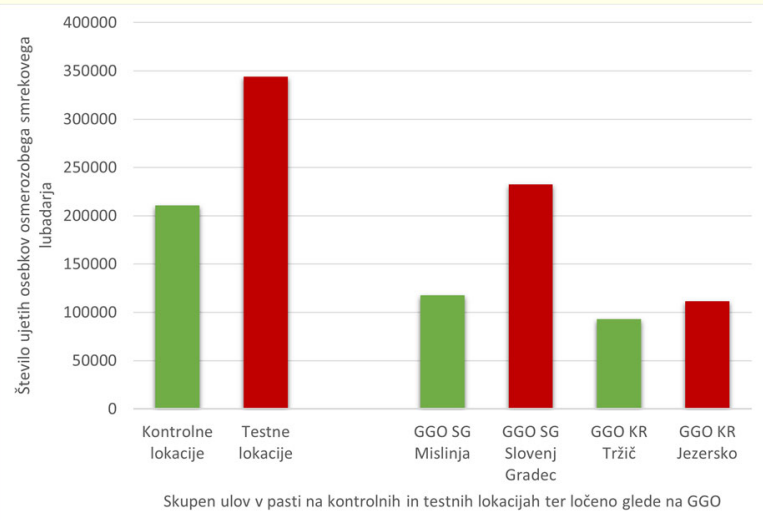

Slika 6: Razlika v ulovu osmerozobega smrekovega lubadarja $\mathrm{z}$ različnimi feromonskimi pripravki med testnimi in kontrolnimi lokacijami.

Pri količini stranskega ulova se je razlika med testnimi in kontrolnimi lokacijami videla samo pri feromonskem pripravku Ipstyp ${ }^{\circledR}$, ki je prav tako pokazal večji stranski ulov na testnih lokacijah. V GGO Slovenj Gradec je bil stranski ulov večji za 51,4 \% in število plenilcev osmerozobega smrekovega lubadarja večji za $87,8 \%$, kot v GGO Kranj.

Časovna dinamika količine ulova osmerozobega smrekovega lubadarja je bila za vse feromonske pripravke zelo podobna. Kljub temu pa se je pri vseh feromonskih pripravkih razlikovala med GGO Kranj in GGO Slovenj Gradec (Slika 7).
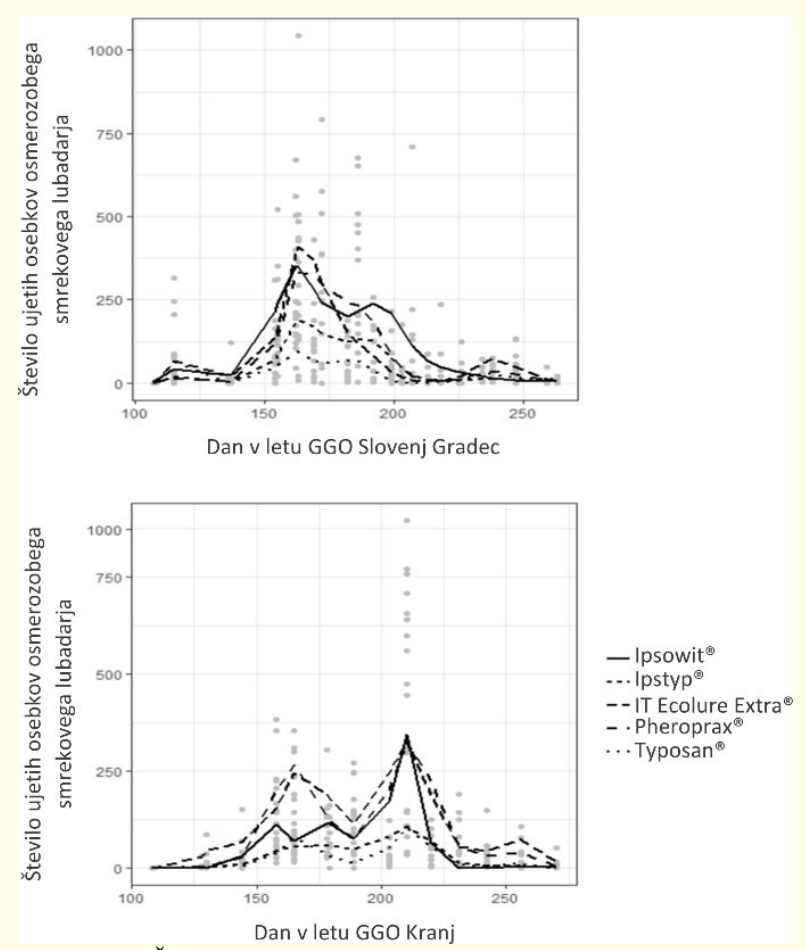

Slika 7: Časovna dinamika količine ulova osmerozobega smrekovega lubadarja z različnimi feromonskimi pripravki v
GGO Kranj in GGO Slovenj Gradec. Prevedena slika iz izvirnega članka Šramel in sod. (2021).

$\mathrm{Za}$ analizo stroškov smo upoštevali nabavno vrednost pasti, kolov za postavitev pasti, feromonskih pripravkov, stroške dela in potne stroške. Stroški dela vključujejo ure za postavitev pasti, pobiranje ulova, menjavanje feromonskih pripravkov in $\mathrm{v}$ našem primeru tudi za pospravilo pasti. Analiza stroškov je pokazala, da stroški dela predstavljajo največji delež (69 \% od celotnih stroškov). Vrednost feromonskih pripravkov predstavlja razmeroma majhen delež skupnih stroškov (13\%) (Slika 8), vendar lahko izbira cenejšega pripravka pred dražjim pomeni končno razliko v ceni tudi do $2.000 €$ za celoletno uporabo v 50 pasteh. Potrebno je izpostaviti, da pasti in kole za postavitev pasti, lahko uporabljamo še nadaljnjih 10 let, medtem ko so ostali stroški prisotni vsako leto.

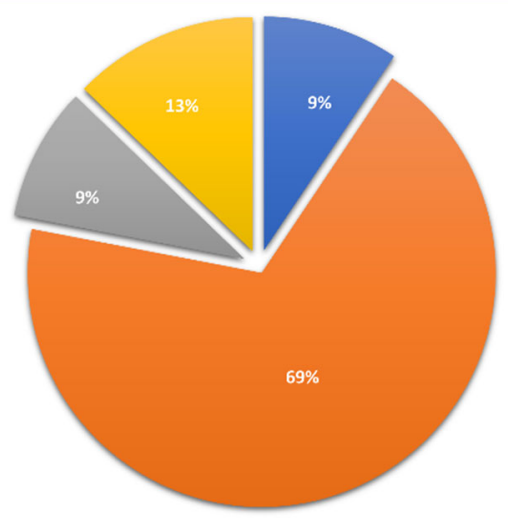

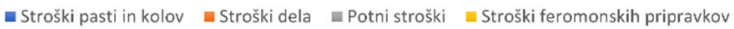

Slika 8: Stroški spremljanja populacije osmerozobega smrekovega lubadarja.

Rezultati so podrobneje predstavljeni v izvirnem delu (Šramel in sod., 2021).

\section{Indeks}

Na podlagi zbranih podatkov smo izdelali indeks za primerjavo vseh petih feromonskih pripravkov glede na izbrane tri lastnosti in ceno (Preglednica 1). V stolpcu z imenom "Učinkovitost" se nahaja vrednost, ki jo predstavlja povprečje, izračunano iz deljenja seštevka ulova osmerozobega smrekovega lubadarja v pasteh izbranega feromonskega pripravka $\mathrm{z}$ najvišjim zabeleženim ulovom osmerozobega smrekovega lubadarja s strani vseh feromonskih pripravkov. "Občutljivost" je vrednost, ki jo dobimo iz povprečja razlik med ulovom osmerozobega smrekovega lubadarja $\mathrm{v}$ pasteh iz testnih in kontrolnih lokacijah izbranega feromonskega pripravka, ki jih delimo $\mathrm{z}$ najvišjo zabeleženo razliko med ulovom osmerozobega smrekovega lubadarja v pasteh na testnih in kontrolnih lokacijah s strani vseh feromonskih pripravkov. "Selektivnost" je vrednost, ki jo predstavlja povprečje, izračunano z delitvijo vrednosti, ki jo dobimo $\mathrm{z}$ delitvijo razmerja med ulovom osmerozobega smrekovega lubadarja in stranskim ulovom za izbrani feromonski pripravek, z najvišjo razliko med ulovom osmerozobega smrekovega lubadarja in stranskim ulovom od vseh feromonskih pripravkov. Iz pridobljenih vrednosti za posamično lastnost smo izračunali "Končni indeks" za 
posamezni feromonski pripravek, ki nam pove, kateri feromonski pripravek je glede na vse izbrane lastnosti najboljši. Za "Končni indeks" smo izračunane vrednosti za posamezno lastnost izbranega feromonskega pripravka (učinkovitost, občutljivost in selektivnost) sešteli in jih delili s številom izračunanih vrednosti, kar je v našem primeru število 3. Pridobljena končna vrednost se nahaja v stolpcu "Končni indeks". Višja kot je vrednost, boljši je feromonski pripravek glede na izbrane lastnosti v primerjavi z drugimi feromonskimi pripravki. V zadnjem stolpcu "Cena" pa je navedena vrednost za 34 feromonskih pripravkov, kolikor smo jih uporabili v celotni sezoni za vsako vrsto feromonskega pripravka (Preglednica 1).

Primerjava lastnosti feromonskih pripravkov in cene (Preglednica 1) kaže, da najdražji feromonski pripravek ni nujno najbolj primeren za naše potrebe. Povedano drugače: višja cena feromonskega pripravka ni zagotovilo, da je pripravek tudi najbolj primeren za naše potrebe.

Preglednica 1: Primerjava izbranih lastnosti in cene feromonskih pripravkov (najvišje vrednosti so izpisane krepko).

Prevedena preglednica iz izvirnega članka Šramel in sod. (2021).

\begin{tabular}{llllll}
\hline Feromoni & Učinkovitost & Občutljivost & Selektivnost & Končni indeks & Cena \\
\hline Ipsowit $^{\circledR}$ & 0,47 & $\mathbf{1 , 0 0}$ & 0,59 & $\mathbf{0 , 6 9}$ & $480,42 €$ \\
Ipstyp $^{\circledR}$ & 0,22 & 0,54 & 0,52 & 0,42 & $236,98 €$ \\
IT Ecolure Extra $^{\circledR}$ & $\mathbf{0 , 5 0}$ & 0,55 & 0,46 & 0,50 & $351,22 €$ \\
Pheroprax $^{\circledR}$ & 0,46 & 0,28 & $\mathbf{0 , 7 3}$ & 0,49 & $610,98 €$ \\
Typosan $^{\circledR}$ & 0,13 & 0,30 & 0,55 & 0,33 & $350,20 €$ \\
\hline
\end{tabular}

\section{Izbira feromonskega pripravka}

Glede na rezultate je od uporabljenih feromonskih pripravkov najboljši Ipsowit ${ }^{\circledR}$, ki ima skupni indeks najvišji $(0,69)$. Prav tako je od vseh petih feromonskih pripravkov tudi najbolj občutljiv $(1,00)$, vendar ima nižjo učinkovitost $(0,47)$ in nižjo selektivnost $(0,59)$. Glede na strošek je ta feromonski pripravek drugi najdražji (Preglednica 1).

Če za spremljanje izberemo najbolj učinkovit feromonski pripravek, IT Ecolure Extra ${ }^{\circledR}(0,50)$, ima ta nižjo občutljivost $(0,55)$ in najmanjšo selektivnost $(0,46)$. Glede na strošek je skoraj za polovico cenejši od najdražjega feromonskega pripravka (Preglednica 1).

V kolikor želimo imeti najmanjši vpliv na stranski ulov oziroma najbolj selektiven feromonski pripravek, vsekakor izstopa Pheroprax ${ }^{\circledR}(0,73)$, ki ima nižjo učinkovitost $(0,46)$ in najmanjšo občutljivost $(0,28)$. Glede na stroške je ta feromonski pripravek najdražji (Preglednica 1).

\section{Zaključek}

Feromonski pripravki imajo različne lastnosti in samo učinkovitost oziroma količina ulova ciljnega organizma ni vedno najbolj pomembna lastnost, ki jo iščemo pri izbiri primernega feromonskega pripravka za spremljanje stanja gozdov ali raziskavo. Ker je težko ugotoviti razlike med feromonskimi pripravki na podlagi podatkov, ki so navedeni na njihovi embalaži, smo mnenja, da lahko s pomočjo predstavljenega indeksa olajšamo izbiro primernega feromonskega pripravka vsaj v primeru osmerozobega smrekovega lubadarja.

Poleg lastnosti, kot so učinkovitost, občutljivost, selektivnost in cena, na izbiro feromonskega pripravka vpliva tudi čas delovanja na terenu, ki pa v omenjeni raziskavi žal ni bil zajet. Predvsem je ta lastnost feromonskih pripravkov pomembna, saj prihaja do odstopanj med navedenim časom trajanja s strani proizvajalca in dejanskim časom trajanja na terenu, na kar so opozorili v raziskavi Zahradník in Zahradníková (2014).

\begin{abstract}
Zahvala
Zahvaljujemo se gozdarjem Zavoda za gozdove Slovenije za pomoč pri postavitvi pasti in vzorčenju na terenu, ter študentki Evi Groznik za pomoč pri razvrščanju vzorcev v laboratoriju. Raziskava je bila opravljena $v$ sklopu projekta Izboljšanje sistema spremljanja ulova smrekovih podlubnikov v kontrolne feromonske pasti in sistema polaganja kontrolnih nastav ter izdelava aplikacije za načrtovanje lokacij in števila kontrolnih pasti ter kontrolnih nastav po ureditvenih enotah Zavoda za gozdove Slovenije (V4-1822), ki sta ga financirala Ministrstvo za kmetijstvo, gozdarstvo in prehrano ter Javna agencija za raziskovalno dejavnost Republike Slovenije. Projekt se je izvajal v sklopu raziskovalne skupine Gozdna biologija, ekologija in tehnologija (P40107) na Gozdarskem inštitutu Slovenije.
\end{abstract}

\section{Viri}

Bakke A., Frøyen P., Skattebøl L. 1977. Field Response to a New Pheromonal Compound Isolated from Ips typographus. Naturwissenschaften, 64: 98-99. https://doi.org/10.1007/BF00437364

de Groot M., Diaci J., Ogris N. 2019. Forest management history is an important factor in bark beetle outbreaks: Lesson for the future. Forest Ecology and Management, 433: 467-474.

https://doi.org/10.1016/j.foreco.2018.11.025

Galko J., Gubka A., Vakula J., Brutovský D. 2010. Comparison of catches of the spruce bark beetle (Ips typographus L.) (Coleoptera: Scolytidae) in pheromone traps of Canadian and European production. Forestry Journal, 56, 4: 337-347.

http://doi.org/10.2478/v110114-009-0017-0

Göktürk T., Akkuzu E., Aksu Y. 2005. Comparing the effectiveness ratios of pheromone lures of Ipsowit ${ }^{\circledR}$,Ipstyp ${ }^{\circledR}$, and Typosan ${ }^{\circledR}$ against ips typographus (L.) (Col.: Scolytidae) Artvin Çoruh Üniversitesi Orman Fakültesi Dergisi, 6, 1: 155-160.

https://doaj.org/article/0b4f67e9408a43bb895e30428b565184

Pernek M. 2002. Analysis of biological efficiency of feromon preparations and types of traps used for capturing bark beetle Ips typographus L. and Pityogenes chalcographus L. (Coleoptera; Scolytidae). Radovi - Sumarski Institut Jastrebarsko, 37, 1: 61-83. https://www.semanticscholar.org/paper/Analysis-of-biological-efficiency-of-pheromone-and-Per-

nek/0990b2913522a85fd5431e3ecf29bc3078032ad0

Šramel N., Kavčič A., Kolšek M., de Groot M. 2021. Estimating the most effective and economical pheromone for monitoring the European spruce bark beetle. Journal of Applied Entomology, 0: 1-14. https://doi.org/10.1111/jen.12853

Zahradník P., Zahradníková M. 2014. Evaluation of the efficacy duration of different types of pheromone dispensers to lure Ips typographus (L.) (Coleoptera: Curculionidae: Scolytinae) Journal of Forest Science, 60: 456-463. http://doi.org/10.17221/15/2014-JFS 